\title{
EXTRACCIÓN Y PURIFICACIÓN DEL ADN DE Moniliophthora roreri HONGO QUE ATACA EL CACAO, EN NORTE DE SANTANDER
}

Por:

Liliana Yanet Suárez Contreras.'

\section{RESUMEN}

Esta investigación tuvo como objetivo definir la metodología de extracción de ADN y purificación para Moniliophthora roreri y aplicarla a 56 aislamientos de Moniliophthora roreri obtenidos en los municipios y corregimientos de Cúcuta, Agua Clara, Sardinata, El Tarra, Tibú, Bucarasica, Teorama y El Zulia del departamento de Norte de Santander (Colombia). Se realizó la extracción de $A D N$, utilizando el protocolo propuesto por Miranda y Sandoval en el año 2000 con algunas modificaciones propuestas por Rocha. Para su purificación se utilizó fenol cloroformo. Una vez se estandarizó el protocolo de extracción, se probó con otros hongos: Metarhizium sp, Botritys cincrea, Fusarium culmorum, Phytophthora cinnamomi. Con este trabajo se pretende continuar con la investigación en el área de Biología Molecular de Moniliophthora roreri y otros fitopatógenos de importancia económica para la región, fomentando así la investigación.

Palabras claves: Moniliophthora roreri, biología molecular, aislamiento de ADN, fitopatógeno.

\section{ABSTRACT}

This research has as objetive to define the methodology of extraction and purification for Moniliophthora roreri and to apply it to 56 isolations of Moniliophthora roreri obtained from Cúcuta, Agua Clara, Sardinata, El Tarra, Tibú, Bucaracica, Teorama and Zulia in Norte de Santander (Colombia). The extraction of DNA was carried out by the protocol proposed by Miranda and Sandoval in 2000, with some proposed modifications by Rocha. To its purification was utilized Chloroform Phenol. Once, it was standarized by the protocol of extraction. It tested with other mushrooms: Metarhizium sp, Botritys cincrea, Fusarium culmorum, Phytophthora cinnamomi. This work intends to continue with the research in the area of Molecular Biology of Moniliophthora roreri and other phytopathogens of economic importance for the region, it promotes the research in micology.

Key words: Moniliophthora roreri, Molecular Biology, Isolation of DNA, Phytopathogen.

\section{INTRODUCCIÓN}

El hongo Moniliophthora roreri es el agente causal de la enfermedad llamada moniliasis, considerada como una de las más grandes afecciones del cultivo de cacao en Colombia y en otros países de Centro y Sur América, por los daños que ocasiona ( Cubillos, 1970).

En Colombia produce pérdidas del 60-95\%, reduciendo en el Norte de Santander la producción (Suárez, 2004).

En Colombia se han realizado pocos estudios sobre la biología del hongo Moniliophthora roreri y su biología molecular; es importante resaltar que el laboratorio de genética molecular de la Universidad Francisco de Paula Santander inicia con este trabajo el de identificar y caracterizar molecularmente fitopatógenos que atacan el cacao a través de metodologías moleculares mediante la estandarización de una técnica que permite la extracción del ADN de Moniliophthora roreri y más adelante de otros fitopatógenos de interés agronómico.

Además, se deben caracterizar los patógenos utilizando la tecnología de los marcadores moleculares (Gostsch, 1997), y así, los planteamientos en molecular han llegado a ser una herramienta para que los micólogos puedan estudiar la sistemática evolución molecular,

\footnotetext{
' Lic. Biología- Química, MSc. Biología, énfasis Genética. Candidata a Doctor en Biotecnología. Docente de tiempo completo del Departamento de Biología. Coordinadora del Laboratorio de Genética Molecular. Universidad Francisco de Paula Santander.lysuarez@bari.ufps.edu.co
} 
Extracción y purificación del ADN de Moniliophthora roreri hongo que ataca el cacao, en Norte de Santander.

poblaciones genéticas de hongos o la interacción planta-hongo. Para este propósito el análisis Restriction Fragment Length Polymorphisms (RFLP), las técnicas basadas en la PCR, semejantes a la amplificación de secuencias polimórficas por un cebador al azar (RAPD) o amplificaciones de regiones genómicas, otras como Inter Simple Sequences Repeat Analysis (ISSR) y Amplified Length Polymorphism (AFLP) son aplicadas. El prerrequisito para tales estudios es el rápido aislamiento de ADN genómico puro de alto peso molecular no solo seguido de un procesamiento de un gran número de muestras simultáneamente sino que también provea reproductibilidad con miras a la restricción, ligación y PCR (Möller y otros., 1992).

En el laboratorio se desarrolló un proyecto previo correspondiente al "Aislamiento e identificación del hongo Moniliophthora roreri a partir de cultivos de cacao ubicados en los municipios de Santiago, Sardinata, Tibú y Puerto Santander". Está investigación permitió el aislamiento de 56 muestras de monilia de diferentes municipios y corregimientos de Norte de Santander: Cúcuta, Agua Clara, Sardinata, El Tarra, Tibú, Bucarasica, Teorama y El Zulia. De los cuales ya se tienen las extracciones de ADN para continuar con los estudios de caracterización molecular de Moniliophthora roreri.

\section{MATERIALES Y MÉTODOS}

\section{Aislamiento y Conservación de Moniliophthora roreri}

Se obtuvieron los aislamientos de Moniliophthora roreri a partir de mazorcas de cacao infectadas con Moniliophthora roreri en el Norte de Santander (Colombia). Se siguió el protocolo de desinfección (Suárez, 2004) y se sembró en cajas de Petri con PDA, las cuales se incubaron a $28^{\circ} \mathrm{C}$ bajo un monitoreo diario durante siete días; luego se cortaron pequeños trozos del agar con el micelio que se pretendía aislar hasta obtener cultivos puros de los que se pasaron repiques en caldo papa dextrosa y se dejaron crecer por ocho días (Suárez, 2004).

\section{Extracción del ADN}

El primer paso para desarrollar experimentos con marcadores moleculares es la extracción del ADN (Rocha, 2002). Un buen método de extracción debe mantener la integridad física y bioquímica del ADN e incrementar sus rangos de pureza y concentración (Sambrok et al. 2001).

A continuación se presenta el protocolo de extracción de ADN de Moniliophthora roreri utilizado en el laboratorio de Genética Molecular de la Universidad Francisco de Paula Santander. Para dicho protocolo se utilizó el propuesto por Miranda y Sandoval (2000), con modificaciones (P. Rocha, Cenipalma 2005, comunicación personal).

Se tomó el micelio crecido previamente $(0,5-0,75 \mathrm{~g})$ en caldo papa dextrosa en un microtubo de $2 \mathrm{ml}$ y se le adicionó un volumen de $500 \mathrm{ml}$ de buffer de extracción $(50 \mathrm{mM}$ Tris- $\mathrm{HCl} \mathrm{pH}=7,5 ; 50 \mathrm{mM}$ EDTA; $2 \%$ de $\mathrm{SDS}$ y $1 \%$ de $\mathrm{Na}_{2} \mathrm{SO}_{3}$ ). Se procedió a macerar la muestra con el buffer de extracción; luego se agitó en vortex por un minuto y posteriormente se centrifugó a $6000 \times$ g, por diez minutos; el sobrenadante se incubó a $70^{\circ} \mathrm{C}$ durante quince minutos. Después, se adicionó un volumen fenol/cloroformo de $(1: 1)$ a cada muestra y se centrifugó a 10.000 × g, por diez minutos. Se transfirió la fase acuosa a otro microtubo y se le agregó un volumen de isopropanol. Se dejó en frío (congelación) 10 minutos, nuevamente se centrifugó a $10.000 \times \mathrm{g}$, durante diez minutos, y el precipitado se secó a $37^{\circ} \mathrm{C}$ y se resuspendió en $50 \mathrm{ml}$ de TE $1 \mathrm{X}$ $\mathrm{pH}=8$ y RNAsa.

\section{Purificación y Verificación del ADN}

Para la purificación del ADN se realizaron tres ensayos. En el primer ensayo se utilizó etanol; en el segundo ensayo se utilizó cloroformo/ alcohol isoamílico y en el último ensayo se probó con solo fenol/cloroformo. 
Extracción y purificación del ADN de Moniliophthora roreri hongo que ataca el cacao, en Norte de Santander.

Las muestras después de ser purificadas fueron verificadas mediante electroforesis en un gel de agarosa al $0.7 \%$ y al $1 \%$. La electroforesis se realizó a 100 V, 20 minutos, y se usó un patrón de fago $\lambda$ digerido con Hind III. Y MAR 2 con los siguientes pesos moleculares de las bandas $(8.9 / 5 / 2.9 / 1.65 /$ $1 / 0.5)$

Ensayos del protocolo de extracción de ADN con otros hongos.

Se realizó la extracción del ADN con el protocolo propuesto a los siguientes hongos: Una cepa de Metarhizium, sp. proveniente del cepario de la Universidad Francisco de Paula Santander. Las cepas Botritys cincrea, Fusarium culmorum, y Phythopthora cinnamomi fueron adquiridas del cepario de la Universidad Pablo de Olavide (Sevilla, España), lugar donde fueron procesadas para poner a punto el protocolo.

\section{RESULTADOS Y DISCUSIÓN}

El protocolo propuesto por Miranda y Sandoval resultó ser el más apropiado al hacer la modificación en la temperatura de incubación de 80 a $70^{\circ} \mathrm{C}$ y el tiempo de refrigeración de 20 minutos a 10 minutos de congelación.

En el momento de la maceración del micelio del hongo no se requiere nitrógeno líquido, y se facilita la manipulación y el peligro al no hacer un correcto uso del nitrógeno líquido. El buffer de extracción no necesita cloruro de litio, ni mercaptoetanol (Ibeas, 2003 y Möller, 1992), reduciendo así algunos costos en el laboratorio.

No hay necesidad de liofilizar el micelio ni usar CTAB como lo propone Anderbrhan y otros., (1999). Con este protocolo se obtuvo ADN de Moniliophthora roreri de buena calidad y cantidad. (Figura.1).

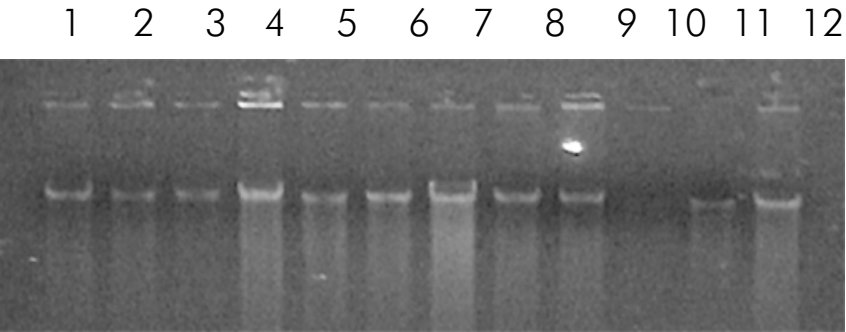

Figura 1 Análisis Electroforético:

Línea 1,4,6 y 11 Muestras de El Zulia

Línea 2,5,9 Muestras de Bucarasica

Línea 3 y 12 Muestras de Sardinata

Línea 7,8 Muestras de El Tarra

Línea 10 Sin Muestra

También el protocolo resultó ser muy eficiente para el aislamiento de otros hongos como Metarhizium, sp, Botritys cincrea, Fusarium culorum,y Phythopthora cinnamomi. (Figura. 2,3,4).

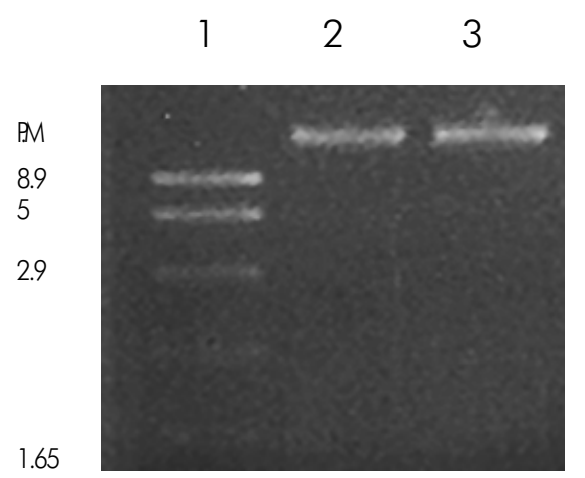

Figura 2 Análisis Electroforético:

(1) marcador de peso molecular, MAR 2.

(2-3) Phytophthora cinnamomi.

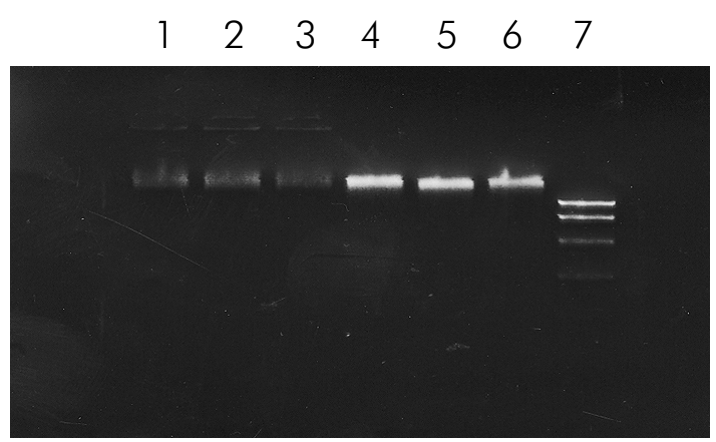

Figura 3 Análisis Electroforético:

(1-3) Botrytis cincrea

(4-6) Fusarium culmorum

(7) marcador de peso molecular, MAR 2. 
Extracción y purificación del ADN de Moniliophthora roreri hongo que ataca el cacao, en Norte de Santander.

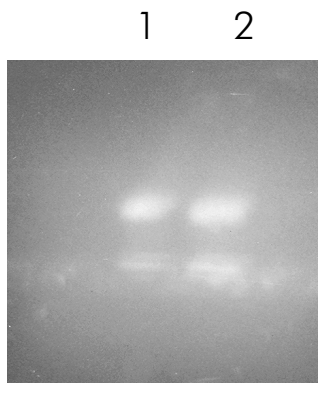

Figura 4 Análisis Electroforético:

$(1,2)$ Metarhizium sp.

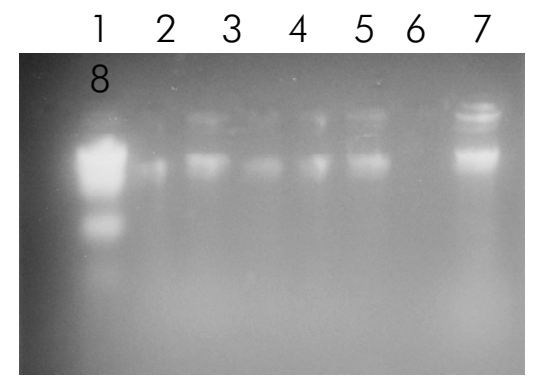

Figura 5 Purificación del ADN Extraído

de Moniliophthora roreri

(1) Marcador. Lambda digerido con Hind III

$(2,3)$ Purificación con Etanol puro

$(4,5)$ Purificación con Cloroformo y Alcohol Isoamílico

(6-8) Purificación con Fenol-Cloroformo. (7) Sin muestra

Esta técnica de extracción de ADN, reduce enormemente el tiempo de procesamiento con respecto a otros métodos. El método propuesto por Dellaporta et al (1983) puede necesitar hasta un día el proceso de extracción del ADN, y por la cantidad de volumen que se utiliza es muy difícil procesar varias muestras a la vez y evita utilizar la proteinasa $K$ ya que la actividad de la proteinasa $\mathrm{K}$ de inactivar nucleasas la hace el calentamiento a $70^{\circ} \mathrm{C}$ durante los quince minutos. El método propuesto por Boehm, 1999, necesita de incubación con la proteinasa $\mathrm{K}$ de por lo menos una hora, hecho que prolonga por más tiempo el procedimiento de extracción o el de la incubación a $65^{\circ} \mathrm{C}$ durante una hora (Du Teau y Leslie, 1999).

El mejor método para la purificación del ADN resultó ser el de Fenol/cloroformo; en el ensayo realizado con etanol y el ensayo realizado con cloroformo/alcohol isoamílico no se obtuvo ADN con la misma calidad y cantidad que al solo usar fenol/Cloroformo. (Figura 5).

Se obtuvo 1 a $2 \mu \mathrm{g} / \mu \mathrm{l}$, de ADN a partir de esta extracción, cantidad suficiente para realizar pruebas moleculares.

En el momento con el protocolo establecido se tienen 56 extracciones de Moniliophthora roreri de los diferentes municipios y corregimientos de Norte de Santander de Cúcuta, Agua Clara, Sardinata, El Tarra, Tibú, Bucarasica, Teorama y El Zulia.

También se probó que el protocolo para la extracción de ADN establecido en este trabajo es útil para otros hongos como Metarhizium, sp, Botritys cincrea, Fusarium culorum, y Phythopthora cinnamom al obtener ADN de gran cantidad y calidad de estos hongos.

\section{CONCLUSIONES}

Mediante este trabajo se logró aislar el ADN de Moniliophthora roreri y se comprobó que este protocolo de extracción es útil para obtener el ADN de otros hongos de diferentes grupos taxonómicos, y se puede aplicar en plantas.

Dados los resultados obtenidos en este trabajo, es posible continuar con la caracterización molecular de Moniliophthora roreri utilizando herramientas moleculares a partir de los 56 extracciones de ADN de Moniliophthora roreri de los diferentes municipios y corregimientos de Norte de Santander (Colombia).

\section{AGRADECIMIENTOS}

Al fondo de Investigaciones Universitarias (FINU)Universidad Francisco de Paula Santander, por el apoyo financiero.

A FEDECACAO- Norte de Santander por facilitar las muestras de Moniliophthora roreri. 
Extracción y purificación del ADN de Moniliophthora roreri hongo que ataca el cacao, en Norte de Santander.

A la Universidad Pablo de Olavide. (UPO). Sevilla, España. Al Dr. José Ignacio lbeas, por facilitar el laboratorio, las muestras de Botritys cincrea, Fusarium culorum, y Phythopthora cinnamomi, y su gran colaboración.

Al Dr. Pedro Rocha. Cenipalma. por su valiosa colaboración.

\section{BIBLIOGRAFÍA}

ANDEBRHAN, T.; FIGUEIRA, A.; YAMADA, M.; CASCARDO, J.; FURTEK, D. 1999. Molecular fingerprinting suggests two primary out breaks of witches'broom disease (Crinipellis perniciosa) of Theobroma cacao in Bahia, Brazil. European Journal of plant Pathology. 105: 167-175 p.

BARÓ, Y. 1998. Caracterización molecular de hongos entomopatógenos. Fitosanidad Vol 2, No. 1 y 2, junio, 67-70 p.

BOEHM, E. W. Fungal Genomic DNA Extraction. (Consultada: diciembre de 1999)

www. protocolonline.net/molbio/DNA/fungalgenomic-dna-extraction.htm

DELLAPORTA, S.L.; WOOD, J.; HICKS, J.B. 1983. A plant molecular DNA minipreparation, version II, Plant Mol. Biol. Rep. 1:12-21.

DU TEAU, N.M. ; LESLIE, J. F A simple, rapid procedure for isolation of DNA for PCR from Gibberella fujikuroi. (Consultada: diciembre de 1999)

www. protocolonline.net/molbio/DNA/simple-rapiddna-extraction.htm

IBEÁS, J. I. 2003. Extracción de ADN de Fusarium sp. Universidad Pablo de Olavide,.

ROCHA, P. 2002. Teoría y práctica para la extracción y purificación del ADN de palma de Aceite. Palmas, vol 23, No. 3, 9-17 p.
ROCHA, P. 2005. Cenipalma. Comunicación personal. Bogotá.

MIRANDA, E., y SANDOVAL, L. 2000. Desarrollo de un método rápido y sencillo para el aislamiento de DNA de especies fúngicas que afectan el arroz y el tabaco. Fitosanidad vol 4, no. 1-2, marzo-junio. 107 $108 \mathrm{p}$.

MÖLLER, E.M; BAHNWEG, G; SANDERMANN, H; GEIGER, H. 1992. A simple and Efficient protocol for isolation of high molecular weight DNA from filamentous fungi, fruti bodies, and infected plant tisúes. Nucleic Acids Research, vol.20, No. 22. 6115-6116 p.

GOTSCH, N. 1997. Cocoa Biotechnology: status, contrainsts and future prospects. Biotechnology Advances, vol 15, No. 2. 333-352 p.

RODRÍGUEZ, S. M.; LÓPEZ, J. A.; ORTEGA, M. A; ÁNGEL, J. E. 2004. Caracterización de aislamientos obtenidos a partir de muestras de arroz con síntomas del "añublo de la vaina provenientes de los llanos orientales de colombia. ICA.

SAMBROOK, J.; RUSELL, D.; 2001. Molecular Cloning, 3rd ed. Cold Spring Harbor laboratory, New York.

SUÁREZ, L. 2004. Aislamiento e identificación del hongo Moniliophthora roreri a partir de cultivos de cacao ubicados en Norte de Santander- Colombia. Universidad Pablo de Olavide. Trabajo de Investigación. Sevilla, España.

Fecha recibido: Octubre 13 de 2005

Fecha aceptación: Noviembre 25 de 2005 